\title{
Validation of Satellite Estimated Solar Ultraviolet Radiation Data with Ground Based data in Kathmandu, Nepal
}

\author{
Niranjan Prasad Sharma \\ Department of Engineering Science and Humanities, Pulchowk Campus \\ Institute of Engineering, Tribhuvan University, Kathmandu, Nepal \\ Email: sharmaniranjanprasad@hotmail.com
}

\begin{abstract}
The main objective of this study is to validate the satellite estimated solar Ultraviolet radiation data with ground based data in Kathmandu $\left(27.72^{\circ} \mathrm{N}, 85.32^{\circ} \mathrm{E}\right)$, located at an elevation of $1350 \mathrm{~m}$, from the sea level. The ground based measurement and the satellite estimation were performed by NILU-UV irradiance meter and EOS Aura OMI satellite respectively. The NILU-UV irradiance meter is a six channel radiometer designed to measure hemispherical irradiances on a flat surface. Meanwhile the Ozone Monitoring Instrument (OMI) on board, the NASA EOS Aura space craft is a nadir viewing spectrometer that measures solar reflected and back scattered light in ultraviolet and visible spectrum. The study is based on OMI and ground based (GB), Ultraviolet Radiation (UVR) data. Considering these data the relative differences between predicted OMI and ground based Ultraviolet Index (UVI) assuming normal distribution $\pm 1 \sigma$ was found to be $24.8 \pm 13.7 \%$ in July. Further study showed that the ratio of predicted OMI, UVI to that determined from ground based measurement is 1.14. Also the relative difference in UVI in corrected condition in summer season was found to be $5.8 \%$. The correlation between predicted UVI and ground based UVI was found to be significant.
\end{abstract}

Keywords: Validation, OMI, NILU-UV, UV radiation, Predicted

\section{Introduction}

Data validation is an essential prerequisite for establishing credibility for satellite data and subsequent use for scientific research. Validation should be viewed as a process, not a task that can be complicated. There is no point at which a satellite data set can be declared "validated". Rather, validation is an ongoing process of comparing the results of the remote sensing measurements performed by a satellite instrument on the Earth atmosphere with correlative data comprised of individual measurements of satellite data products by ground-based, airborne or space-borne sensors that are co-located in space and time. Over time the state of the satellite instrument will be changing, the composition and behavior of the Earth atmosphere may be changing, the availability of correlative data will be changing, and the scientific questions raised and pursued with the derived satellite data products may be changing. Establishing the quality of the satellite data product record therefore requires a continuous approach [3].

OMI, the Ozone Monitoring Instrument flying on Aura, is the latest of a series of ozone mapping instruments. In terms of the long term ozone data record OMI can be considered an advanced version of the total ozone mapping spectrometer (TOMS). A series of TOMS instruments flew on Nimbus 7 (November 1978 to May 1993), Meteor 3 (August 1991 to December 19940 and Earth 
Probe (August 1996 to December 2005). OMI continues this time series of global total column ozone measurements.

A sixth channel NILU-UV moderate-bandwidth filter instrument is also used to measure the ground based ultraviolet radiation data.

The main goal of this paper is to analyze and report OMI and GB data for the year 2011. Also the purpose of this study is to gauge the quality of the OMI, UV data product with ground based NILUUV data. Therefore, the ratio, relative difference and seasonal variation of UVI in the measurement site is analyzed and reported. The relative percentage difference with confidential interval of $\pm 1 \sigma$ was found to be significant. Meanwhile, the observed data are not uniformly distributed and because of this mean values were taken into consideration.

\section{Methodology}

\subsection{Satellite Observation}

OMI, the Ozone Monitoring Instrument is a Dutch-Finish contribution to EOS-Aura. OMI is a nadir viewing, wide swath, ultraviolet-visible (UV-VIS) imaging spectrometer that provides daily global measurements of the solar radiation backscattered by the Earth's atmosphere and surface, along with measurements of the solar irradiance. Full instrument details of OMI have been given elsewhere [6]. But details relevant to ozone retrieval are summarized here. Unlike the heritage TOMS instruments which measure ozone at six discrete wavelengths from $306 \mathrm{~nm}$ to $380 \mathrm{~nm}$ [2], OMI measures the complete spectrum from $270 \mathrm{~nm}$ to $500 \mathrm{~nm}$ at an average spectral resolution of $0.5 \mathrm{~nm}$. OMI combines the advantages of GOME and SCIAMACHY [1], measurement of the complete spectrum in the ultraviolet/visible wavelength range, with the advantages of TOMS, complete spatial coverage of the earth. Each of the two OMI optical channels, UV and VIS, has a two- dimensional CCD detector. One dimension of the CCD is used to cover the spectrum, while the other gives spatial coverage. The UV channel consists of two sub-channels: the UV-1, ranging from 270 to $310 \mathrm{~nm}$, and the UV-2, ranging from 310 to $365 \mathrm{~nm}$. The total ozone retrieval is based on measurements from the UV-2 detector. The VIS- channel covers the range from 365 to $500 \mathrm{~nm}$ [3].

The nadir pointing telescope of OMI has a very large field of view of $114^{\circ}$ perpendicular to the flight direction of the satellite. This gives OMI a swath width of $2600 \mathrm{~km}$, consisting of 60 individual pixels along the swath. The instrument achieves complete daily global coverage of the sunlit earth. The state of the art CCD detectors render a very high spatial resolution of $13 \mathrm{~km} * 24 \mathrm{~km}$ at nadir. The small ground pixel size enables OMI to look "in between" the clouds, giving better reach into the troposphere for retrieving tropospheric composition information than any other UVVIS backscatter instrument flown to date [3].

\subsection{Ground based measurement}

Kathmandu $\left(27.72^{\circ} \mathrm{N}, 85.32^{\circ} \mathrm{E}\right)$ is located at an elevation of $1350 \mathrm{~m}$ from the sea level. The instrument used during the measurement periods were the NIL-UUV irradiance meter. NILU-UV is a six-channel moderate-bandwidth filter instrument. Five of the channels are in the UV with center wavelengths at 305, 312, 320, 340, and $380 \mathrm{~nm}$ and a bandwidth $10 \mathrm{~nm}$ at FWHM. The sixth channel measures the so-called photo synthetically active radiation. It covers wavelengths between 400 and $700 \mathrm{~nm}$ with a bandwidth of $300 \mathrm{~nm}$ at FWHM. The front optics consists of a flat Teflon diffuser followed by custom-made interference filters from Barr Associates, Inc., Westford, 
Mass. To minimize stray-light problems the five UV channels in addition have UG-11 and read leak filters. For the same reason the 305, 312, and $320 \mathrm{~nm}$ channels are equipped with individual specified short-pass filters. For all channels the radiation is recorded by S1226-8BQ silicium detectors from Hamamatsu. The instrument is the temperature stabilized at $50^{\circ} \mathrm{C}$. It records data in a built in data logger within a minute time resolution. The data logger has the capacity to store 3 weeks of 1 min averages. By interfacing the instrument to a computer using a RS-232 port, data with 1-sec time resolution may be recorded. The total weight of the instrument ready for operation is $3.3 \mathrm{~kg}$. The instrument is weatherproof and designed to operate in harsh environments [8].

\section{Results and discussion}

The study is mainly concerned with the validation of OMI - UVI with NILU-UVI data of Kathmandu for the year 2011. This validation is performed by comparing the predicted OMI values with the original values for the year 2012. The predicted value in turn is obtained by first performing a fourth degree fit on the OMI and GB data for the year 2011 generating an equation and then the data of 2012 is fit into it. Alongside, the ratio, correlation and the relative difference under normal distribution between OMI-UVI with GB-UVI are also analyzed. Furthermore, the ratio between OMI and GB, UVI as a function of seasons are also studied. The analysis was done for all sky conditions.

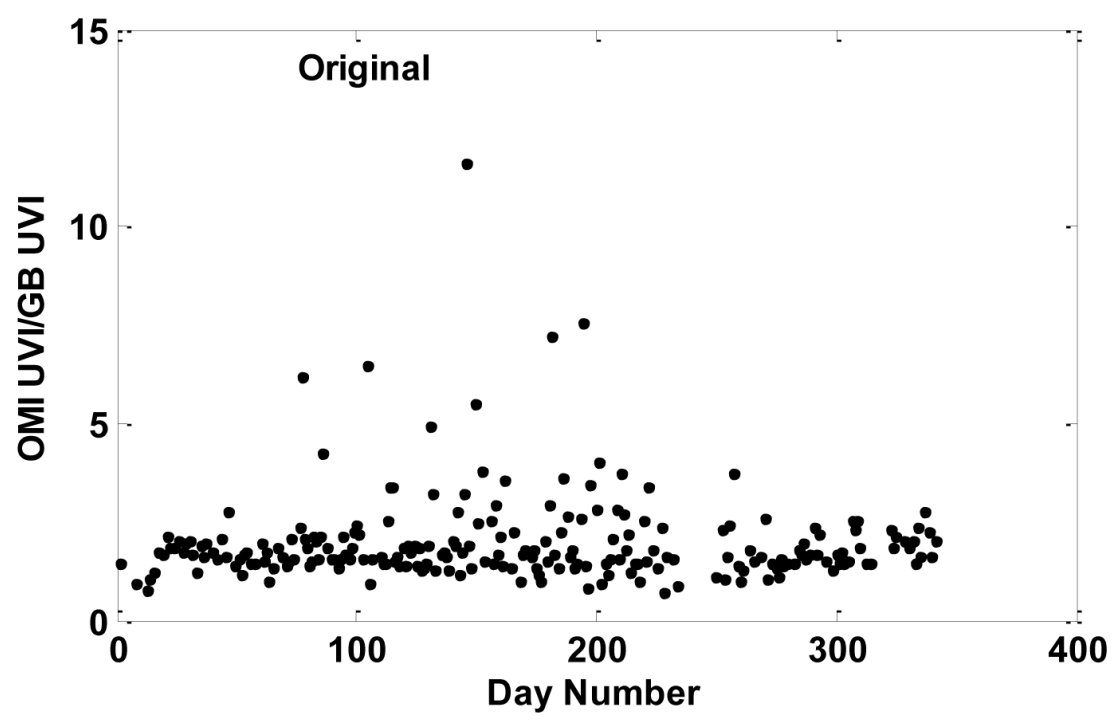

Figure 1: Ratio between satellite UV Index and ground based UV Index

The ratio between original OMI-UV and GB-UV before correction is 1.99 as shown in figure 1 . The above result shows that the noon time UVI obtained from OMI generally overestimates the 
noon time ground based UVI. After correction this ratio dropped and the new ratio between the corrected OMI-UVI and GB-UVI were found to be 1.14 as shown in figure 2.

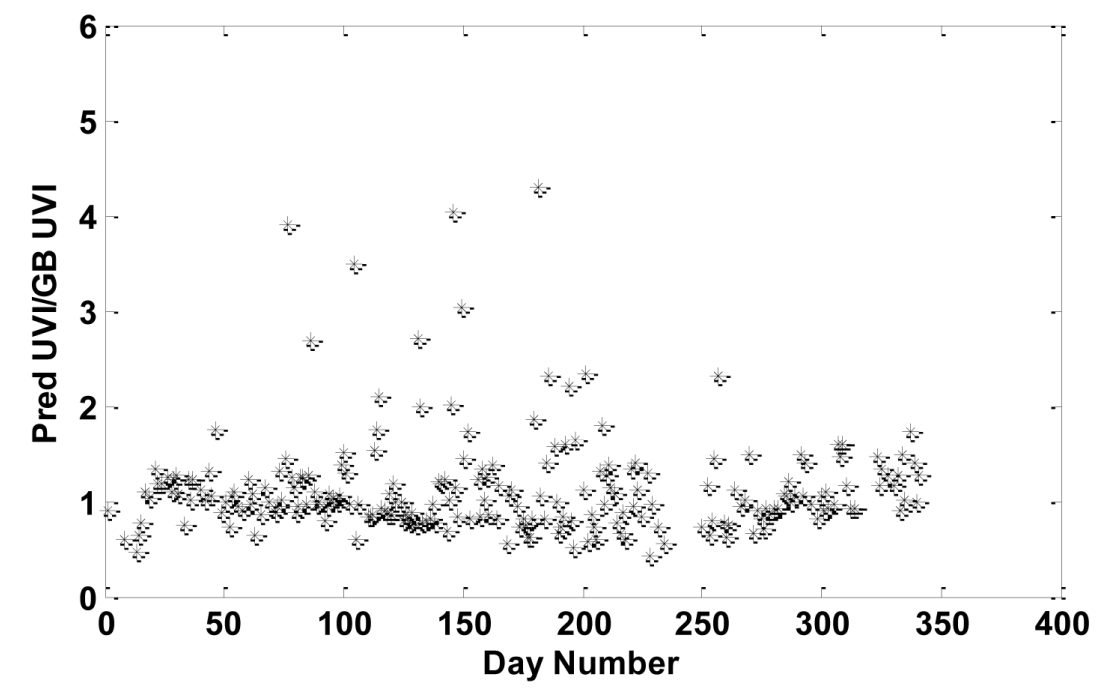

Figure 2: Ratio between predicted UV Index and ground based UV index

The above observation clearly shows that the ratio for the considered sites lied very close to 1 which enables us to conclude that the corrected OMI-UVI data obtained after prediction are valid. This fact is also confirmed by [5] which states that the ratio of OMI to ground measured UV lies between 0.9 and 1.5 and strongly depends on the aerosol optical depth. Also the statement of [4], that the median ratio of the OMI derived dose to the ground based dose in Boulder $\left(39.99^{\circ} \mathrm{N}\right.$, $-105.26^{0} \mathrm{E}, 1650 \mathrm{~m}$. a.s.l) is 1.15 aids our finding.

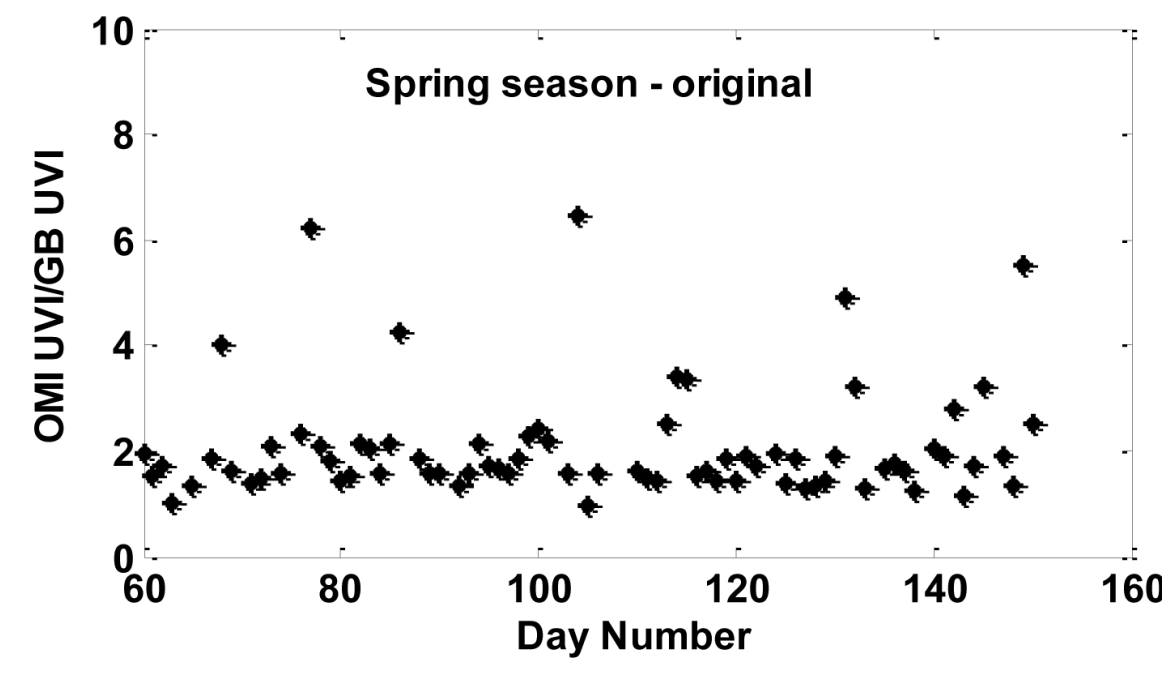


Figure 3: Ratio between satellite UV Index and ground based UV Index in spring season

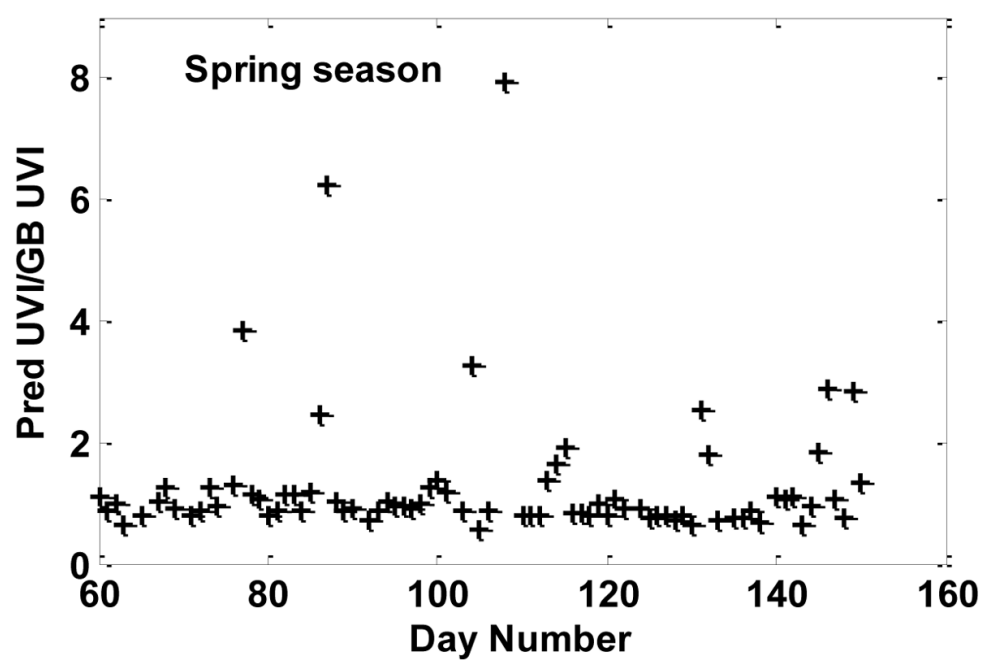

Figure 4: Ratio between predicted UV Index and ground based UV index in spring season

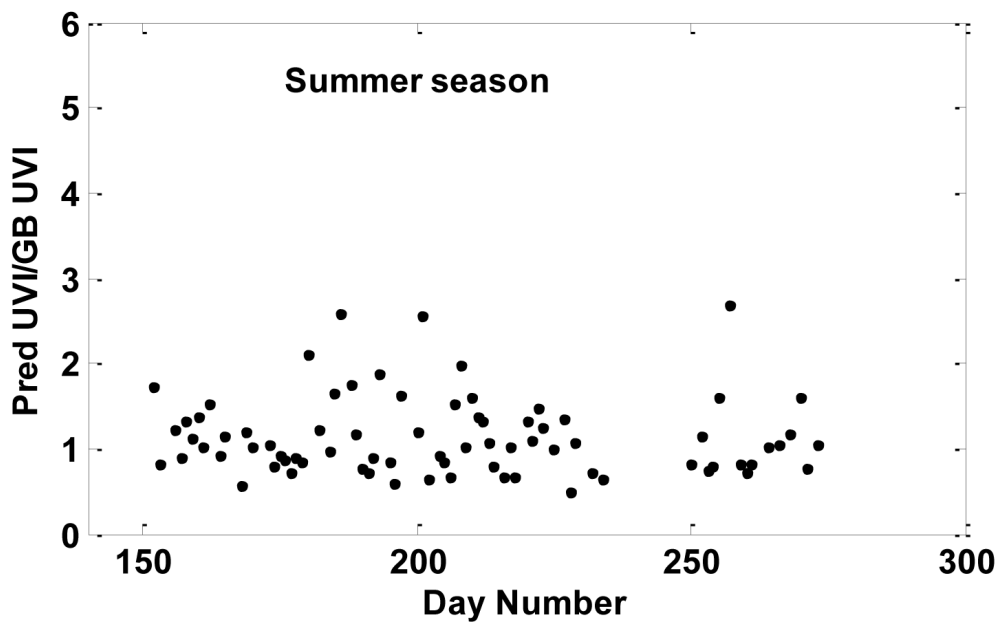

Figure 5: Ratio between predicted UV Index and ground based UV index in summer season

Figure 3 showed that the ratio of original OMI-UVI and GB-UVI in spring season before correction was 2.75 while after the correction the ratio dropped to 1.43 as shown in figure 4 . Meanwhile the average difference and RMS value in UVI in the same season was $8.13 \%$ and 2.04 respectively. The corrected summer season UVI ratio was found to be 1.14 as shown in figure 5. Similarly the average difference and RMS value in the summer season was $5.85 \%$ and 2.30 respectively. The above observation also showed that the UVI ratio in spring season is higher than that in summer season. This is because the spring in Nepal is drier with wind-blown dust which results in attenuating the UV radiation reaching the earth surface. Also the ratio between predicted UVI and ground based UVI in spring and summer season are mostly very close to 1.00 . The gap in the figure represents data missing. The relative difference between corrected OMI and GB data with the corresponding standard deviation was found $2.2 \pm 16.6 \%$ in February as shown in figure 6 . 
Further analysis showed fluctuation in mean difference between OMI and GB data and relatively large standard deviations.

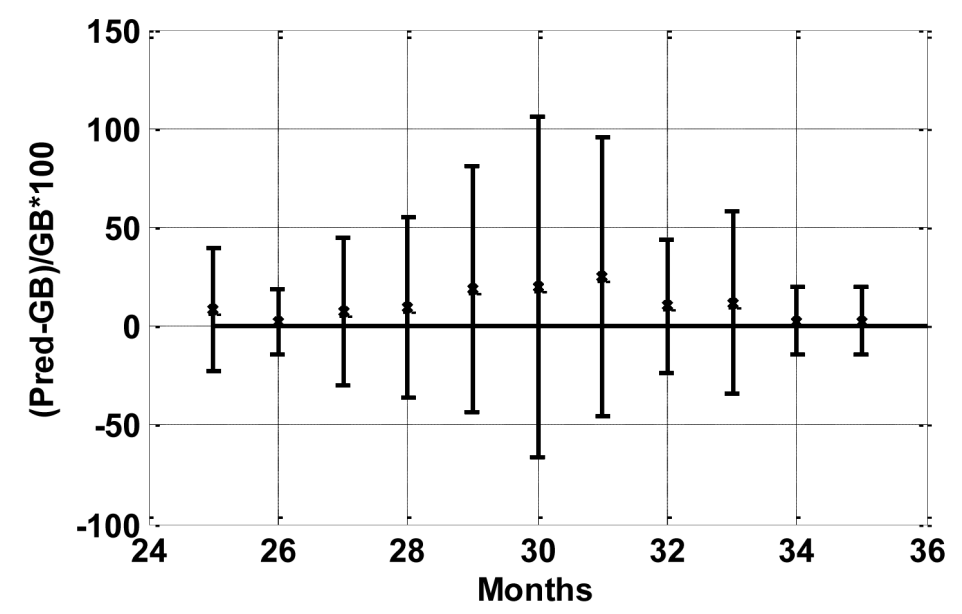

Figure 6: Relative difference between predicted UV Index and ground based UV Index

These large standard deviations is due to cloudy condition which is also agreed upon by [7] which states that under all sky conditions the comparisons showed very small mean difference and relatively large standard deviations for total UV-B and for EUV radiation. The large standard deviations are attributed to the in-homogeneity in sky condition and mobility of cloudy scenes, which renders an inaccurate match between satellite and surface measurements. Furthermore, [5] stated that large standard differences may result from the match between satellite and surface observations. It is also noted, that a satellite observation represents a value averaged over an area of $50 * 50 \mathrm{~km}^{2}$ or larger, while a ground measurement usually corresponds to a much smaller area.

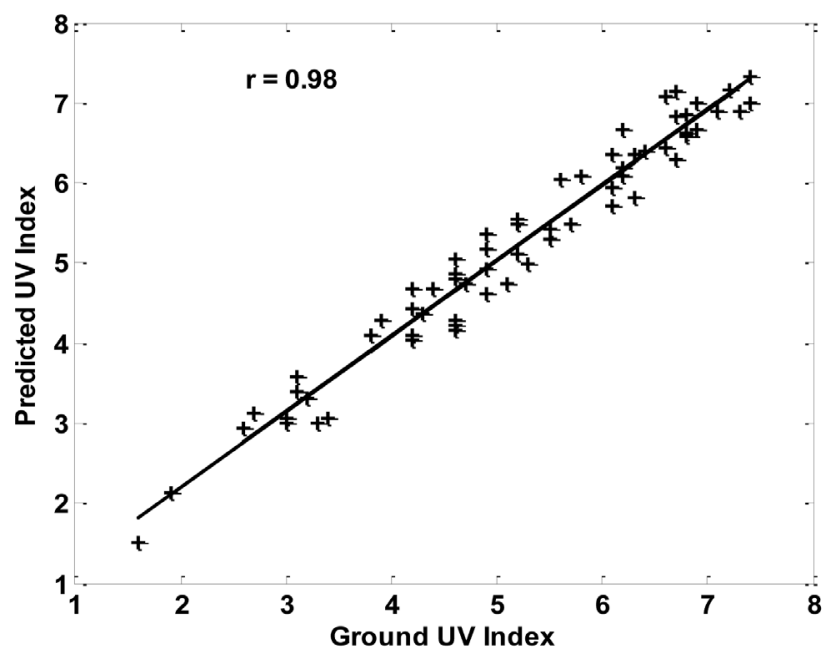

Figure 7: Scatter plot of predicted UV Index versus ground based UV Index

The correlation of scatter plot between predicted UV Index and ground based UV Index was found to be 0.98 as shown in figure 7 . This result also helps to validate the ultraviolet radiation data. Finally, the OMI-UVI data of the year 2012 was fit into the equation generated from OMI-UVI 
data of the year 2011. In this case the mean ratio between predicted UVI and GB, UVI was found to be very close to 1 . Thus we can conclude that satellite ultraviolet data are validated.

\section{Conclusions}

In this study, the corrected OMI and GB data for the year 2011 were studied, analyzed and reported. In an average, the ratio of corrected OMI with GB data for Kathmandu was found to lie near 1 and this observation provided sufficient evidence to consider the validity of OMI data. On analysis, the correlation coefficient between predicted UV Index and ground based UV Index was found to be 0.98 . Furthermore, the average difference in UVI in monsoon season before correction $52.5 \%$ while after correction it was $5.8 \%$. It was also found that, the corrected UVI ratio in spring season was slightly higher than in summer season. Overall data analysis showed that the satellite estimated ultraviolet radiation data with ground based data are validated.

Acknowledgements: The author is acknowledging to Solar Radiation and Aerosols in the Himalayan Region. The author is also grateful to NASA for providing satellite data.

\section{References}

[1] Burrows JP, Weber M, Buchwitz M, Rozanov V, Weibenmayer L, Richter A, Debeek R, Hoogen R, Bramstedt K, Eichmann KU and Eisinger M (1999), The Global Monitoring Experiment (GOME): Mission concept and first scientific results. Journal of Atmospheric Sciences, 56, 151175.

[2] McPeters RD, Bhartia PK, Krueger AJ, Herman, JR, Wellemeyer, CG, Seftor, CJ, Jaross G, Torres O, Moy, Leslie, Labow G, Byerly W, Taylor S L, Swissler T and Cebula RP (1998), Earth Probe Total Ozone Mapping Spectrometer (TOMS) Data Products User's Guide. NASA/ TP-1998-206895, NASA, Washington, D.C.

[3] McPeters R, Kroon M, Labow G, Brinksma E, Balis D, Petropavlovskikh, Veefkind JP, Bhartia PK and Levelt PF (2008), Validation of the Aura Ozone Monitoring Instrument total column ozone product. Journal of Geophysical Research, 113.D15S14, doi:10.1029/2007JD008802,2008.

[4] Tanskanen A, Lindfors A, Matt A, Krotkov N, Herman J, Kaurola J, Koskela T, Lakkala K, Fioletov V, Bernhard G, Mckenzie R, Kondo Y, O'Neil M, Slaper H, DenOuter P, Bais AF, Tamminen J (2007), Validation of daily erythemal doses from ozone Monitoring Instrument with ground based UV measurement data. J. Geophys. Res., 5(112), D24S44, doi: 10.1029/2007JD008830.

[5] Weihs P, Blumthaler M, Rieder HE, Kreuter A, Simic S, Laube W, Schmalwieser AW, Wagner JE, Tanskanen A (2008), Measurements of UV irradiance within the area of one satellite pixel. Atoms. Chem. Phys., 8, 5615-5626.

[6] Levelt PF, Van den Oord GHJ, Dobber MR, Malkki A, Visser, H, de Vries J, Stammes P, Lundell $\mathrm{J}$ and Saari H, (2006), The Ozone Monitoring Instrument, IEEE Transaction on Geoscience and Remote Sensing, 44(5), 1093 - 1101

[7] Wang P, Li Z, Cihlar J, Wardle D and Kerr J (2000), Validation of an UV inversion algorithm using Satellite and surface measurements. Journal of Geophysical Research, $105 \mathrm{D}_{4} 5037-5048$

[8] Hoiskar B, Haugen R, Danielsen T, Kylling A, Edvardsen K, Dahlback A, Johnsen B, Blumthaler $\mathrm{M}$ and Schreder J (2003), Multi-channel moderate bandwidth filter instrument for measurement of the ozone - column amount, cloud transmittance, and ultraviolet dose rates. Appl.Opt., 42(18), $3472-3479$. 